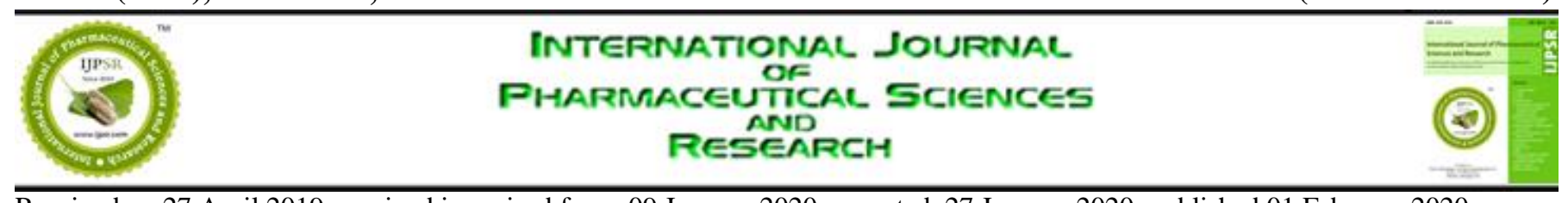

Received on 27 April 2019; received in revised form, 09 January 2020; accepted, 27 January 2020; published 01 February 2020

\title{
DEVELOPMENT AND CHARACTERIZATION OF POLYMERIC MICROPARTICLES CONTAINING MURRAYA KOENIGII LEAVES EXTRACT FOR MANAGEMENT OF DIABETES MELLITUS
}

Neelima Salvi *1 and Gajendra Pratap Choudhary ${ }^{2}$

Department of Pharmaceutics ${ }^{1}$, Smriti College of Pharmaceutical Education, Indore - 452010, Madhya Pradesh, India.

School of Pharmacy ${ }^{2}$, Devi Ahilya Vishwavidyalaya, Indore - 452001, Madhya Pradesh, India.

Keywords:

Particulate system, Plant extract, Murraya koenigii, Diabetes mellitus

\section{Correspondence to Author:}

Neelima Salvi

Department of Pharmaceutics, Smriti College of Pharmaceutical Education, Indore - 452010, Madhya Pradesh, India.

E-mail: salvi.neelima@gmail.com

\begin{abstract}
Objective: Formulation and development of polymeric microparticles containing murrayanol for better treatment of diabetes mellitus. Methods: Successive solvent extraction of leaves of Murraya koenigii plant was done. The active constituent of leaves that is murrayanol was isolated and identified through HPLC and FTIR. Polymeric microparticles were selected as a carrier system and formulated by the solvent evaporation method. Characterization and performance evaluation of particulate system loaded with herbal plant extract of the Murraya koenigii leaves was done. Results: These results suggest that the polymeric microparticles are not only effective in the rapid attainment of high drug concentration in the body and also maintain the same over a prolonged period of time. Microparticles were formulated and characterized for the particle size, shape and its distribution, percentage drug entrapment and in-vitro drug release profile along with the stability studies. Invivo tissue distribution studies on albino rats suggested the accumulation of formulations in the different organs. Conclusion: Prolonged release of natural drug from the carrier system, decrease the dosing frequency and also decrease the dose size. Better results than marketed synthetic anti-diabetic drugs.
\end{abstract}

\section{INTRODUCTION: Curry leaves (Murraya} koenigii) is another Indian medicinal plant, which has enormous traditional values against various diseases and many bioactive compounds have been isolated from this plant ${ }^{1}$. Murraya koenigii commonly known as curry leaves belongs to family Rutaceae $^{2}$. By combining natural constituent with the novel carrier system is a much better concept in case of diabetes; in which daily dosing regimen is approx of 3-4 drugs ${ }^{3}$.

\begin{tabular}{|l|l|}
\hline QUICK RESPONSE CODE & DOI: \\
\hline DOI link: http://dx.doi.org/10.13040/IJPSR.0975-8232.11(2).774-79 \\
\hline
\end{tabular}

\section{Plant Profile:}

- Botanical Name

- Hindi Name

- English Name

- Family

- Parts of Plant used

$:$ Murraya koenigii
$:$ Meetha Neem
$:$ Curry leaf
$:$ Rutaceae
$:$ Leaves $^{3}$

\section{Scientific Classification:}

- Kingdom

$$
\text { : Plantae }
$$$$
\text { - Subkingdom : Tracheobionta }
$$$$
\text { - Superdivision : Spermatophyta }
$$$$
\text { - Division : Magnoliophyta }
$$$$
\text { - Class : Magnoliopsida }
$$$$
\text { - Subclass : Rosidae }
$$$$
\text { - Order : Sapindales }
$$$$
\text { - Family : Rutaceae }
$$ 
- Genus

- Species
Murraya J. Koenig ex L.

: Murraya koenigii (L.) sperng

MATERIALS AND METHODS: Crude drug or plant part of Murraya koenigii was collected from agriculture college, Indore. Their identification and authentification were confirmed by the Department of Botany, Holkar Science College, Indore by correlating their morphological and microscopic characters with those given in the literature. The leaves were collected, cleaned well to remove all the dirty material and were shade dried and then powdered transferred into airtight containers with proper labeling for further use. Chloroform, ethanol, methanol, petroleum ether and ethyl acetate were purchased from S. K. Traders, Indore. All solvents were analytical grade.

\section{Preparation of Extracts:}

Petroleum Ether Extract: The coarsely powdered, dried leaves $(50 \mathrm{~g})$ were extracted with $300-500 \mathrm{ml}$ petroleum ether by hot extraction process (Soxhlet) for $4 \mathrm{~h}$. After completion of extraction, the solvent was removed by distillation and concentrated in vacuo.

Chloroform Extract: The marc left after petroleum ether extraction was dried and extracted with $300 \mathrm{ml}-500 \mathrm{ml}$ chloroform by the hot extraction process (Soxhlet) for $4 \mathrm{~h}$. After completion of extraction, the solvent was removed by distillation and concentrated in vacuo.

Ethyl Acetate Extract: The marc left after the extraction of the chloroform extraction was dried and extracted with $300 \mathrm{ml}-500 \mathrm{ml}$ ethyl acetate by the hot extraction process (Soxhlet) for $4 \mathrm{~h}$. After completion of extraction, the solvent was removed by distillation and concentrated in vacuo.

Methanol Extract: The marc left after the ethyl acetate extraction was dried and extracted with 300 $\mathrm{ml}-500 \mathrm{ml}$ methanol by the hot extraction process (Soxhlet) for $4 \mathrm{~h}$. After completion of the extraction, the solvent was removed by distillation and concentrated in vacuo.

Ethanol Extract: The marc left after the methanol extraction was dried and extracted with $300 \mathrm{ml}$ $500 \mathrm{ml}$ ethanol by the hot extraction process (Soxhlet) for $4 \mathrm{~h}$. After completion of the extraction, the solvent was removed by distillation and concentrated in vacuo.

The above extracts were used for phytochemical studies. The extractive values for each extract were calculated and recorded.

Isolation and Fractionation of Murrayanol: The drug powder was taken in the Soxhlet extractor and was extracted using ethanol for $72 \mathrm{~h}$. After the extraction was over the solvent was recovered by distillation and the residue was concentrated in vacuo. The extract obtained was then stored in a desiccator.

$50 \mathrm{gm}$ of the ethanolic extract obtained was suspended in distilled water $(200 \mathrm{ml})$ in small amounts. It was extracted successively and exhaustively with solvents in increasing order of polarity viz. petroleum ether $\left(60-80{ }^{\circ} \mathrm{C}\right)(200 \mathrm{ml} \times$ $5)$, solvent ether $(200 \times 5)$ and ethyl acetate $(200 \times$ $3)$. Each fraction was washed with distilled water $(5 \mathrm{ml})$, dried over anhydrous sodium sulfate and freed of solvent by distillation. The aqueous remnant was freed of organic solvent by distillation under reduced pressure and then evaporated to dryness on a water bath. The yield of each extract was recorded and subjected to chemical investigation.

TABLE 1: SUCCESSIVE EXTRACTIVE VALUES OF THE POWDERED LEAVES OF MURRAYA KOENIGII

\begin{tabular}{ccc}
\hline S. no. & Extracts & Yield $(\%$ w/w $)$ \\
\hline 1 & Petroleum ether extract & 2.41 \\
2 & Chloroform extract & 2.72 \\
3 & Ethyl acetate extract & $2 . .05$ \\
4 & Methanol extract & 4.11 \\
5 & Ethanol extract & 3.90 \\
\hline
\end{tabular}

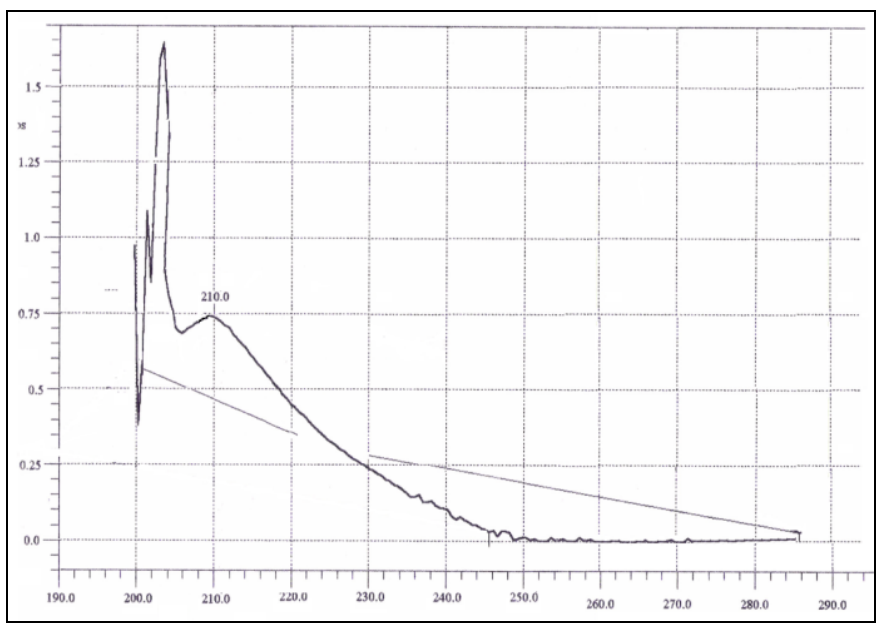

FIG. 1: UV SPECTRA OF MURRAYANOL 


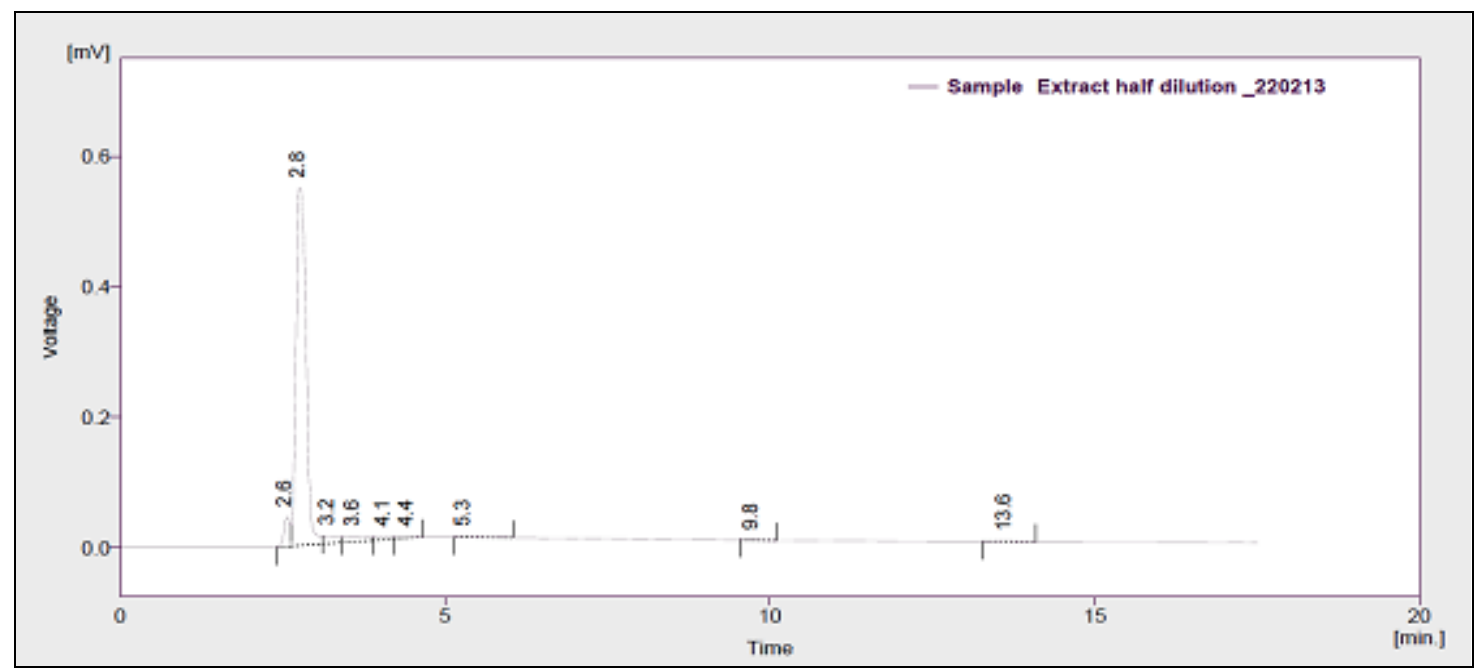

FIG. 2: HPLC SPECTRA OF ISOLATED MURRAYANOL

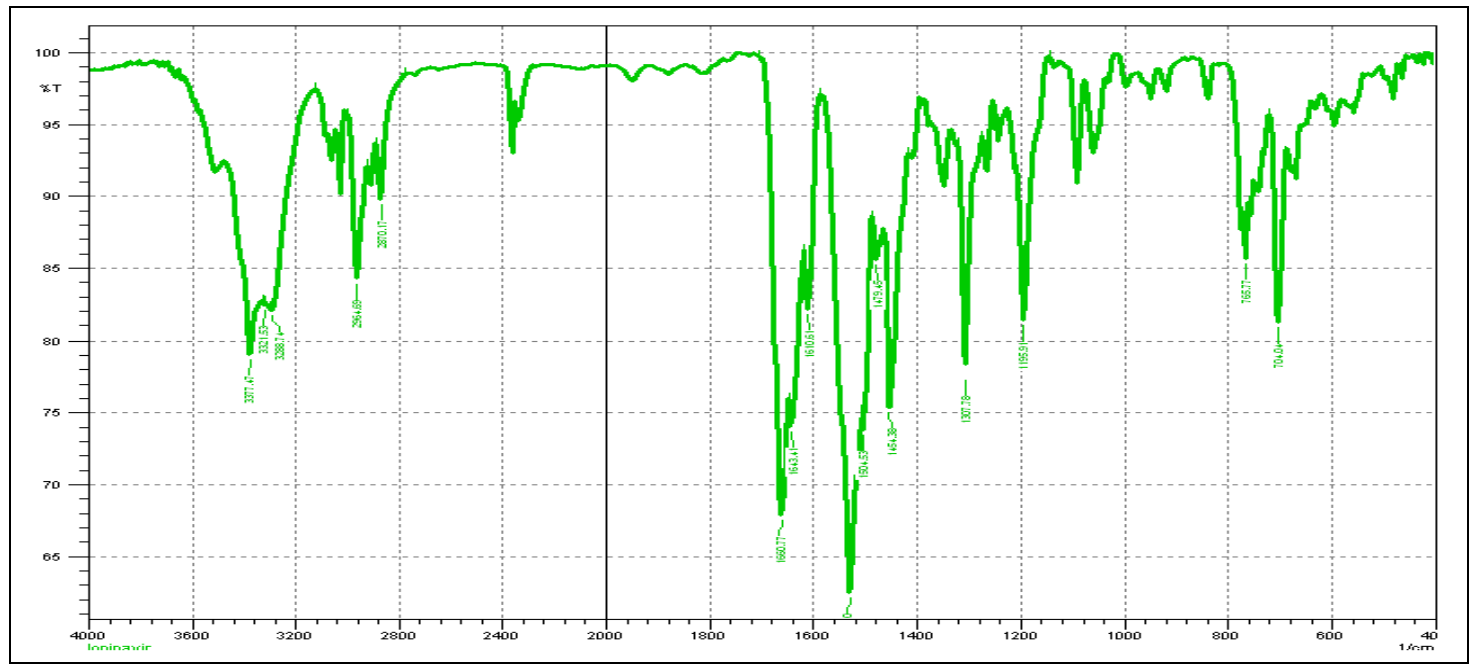

FIG. 3: IR SPECTRA OF ISOLATED MURRAYANOL

Phytochemical Study of Murraya koenigii: Isolated murrayanol from murraya koenigii showed a melting point at $188{ }^{\circ} \mathrm{C}$ which was in agreement with the standard range of $180-189^{\circ} \mathrm{C}$, as reported. The $\mathrm{R}_{\mathrm{f}}$ values of isolated and standard murrayanol in several mobile phases are shown in table below:

TABLE 2: COMPARISON BETWEEN THE $R_{f}$ VALUES OF ISOLATED AND STANDARD MURRAYANOL IN DIFFERENT MOBILE PHASE (TLC)

\begin{tabular}{ccc}
\hline Solvent system in TLC & $\mathbf{R}_{\mathbf{f}}$ value of isolated murrayanol & $\mathbf{R}_{\mathbf{f}}$ value of standard murrayanol \\
\hline Ethyl acetate : formic acid : acetic acid : water & 0.38 & 0.35 \\
\hline
\end{tabular}

TABLE 3: COMPARISON BETWEEN THE $R_{f}$ VALUES OF ISOLATED AND STANDARD MURRAYANOL IN DIFFERENT MOBILE PHASE (PAPER CHROMATOGRAPHY)

\begin{tabular}{ccc}
\hline Solvent system in Paper Chromatography & $\mathbf{R}_{\mathbf{f}}$ value of isolated murrayanol & $\mathbf{R}_{\mathbf{f}}$ value of standard murrayanol \\
\hline Isopropyl alcohol : water & 0.56 & 0.58
\end{tabular}

Pharmaceutical Screening of Active Acute Toxicity Study: The acute toxicity study is Constituent: All experiments were in agreement used to establish the therapeutic index, i.e. the ratio with ethical guidelines for investigations of the between the pharmacologically effective dose and experimental plant in the conscious animal. The research protocol was approved by the Institutional

Animal Ethics Committee (IAEC/SCOPE/1415/106). lethal dose on the same strain and species $\left(\mathrm{LD}_{50} / \mathrm{ED}_{50}\right)$. The animals were divided into four groups and each group consisted of five mice. The defined or fixed-dose level of aqueous and ethanolic extracts $(2000 \mathrm{mg} / \mathrm{kg})$ was given orally to 
identify a dose producing evident toxicity. The animals were observed continuously for $2 \mathrm{~h}$ for behavioral, neurological and autonomic profiles.
The toxicity signs were observed after $24 \mathrm{~h}$ till fourteen days for any lethality or death.

TABLE 4: RESULT OF ACUTE TOXICITY STUDY OF MURRAYANOL

\begin{tabular}{cccccc} 
S. no. & Group & No. of & \multirow{2}{c}{$\begin{array}{c}\text { Treatment } \\
\text { animal used }\end{array}$} & \multicolumn{2}{c}{ No. of animals recovered after study } \\
\cline { 3 - 6 } & & 5 & 2000 & $\mathbf{2 4 ~ h}$ & $\mathbf{7 2 ~ h}$ \\
\hline 1 & Group A (Alcoholic extract) & 5 & 2000 & 5 & 4 \\
2 & Group B (Aqueous extract) & 5 & 5 & 5 \\
\hline
\end{tabular}

Oral Glucose Tolerance Test: Animals were divided into nine groups and each group consisted of six rats.

Overnight fasted rats were used for the study.

Group I: Normal control rats administered saline $(0.9 \% \mathrm{w} / \mathrm{v})$.
Group II: Diabetic rats administered standard drug Glibenclamide $(2.5 \mathrm{mg} / \mathrm{kg})$ daily.

Group III: Diabetic rats administered test sample $(50 \mathrm{mg} / \mathrm{kg})$.

Group IV: Diabetic rats administered the test sample $(100 \mathrm{mg} / \mathrm{kg})$.

TABLE 5: EFFECT OF MURRAYANOL FROM MURRAYA KOENIGII ON ORAL GLUCOSE TOLERANCE TEST IN RATS

\begin{tabular}{cccccc}
\hline S. no. & Treatment & \multicolumn{3}{c}{ Fasting blood glucose level (mg / dl) } \\
\cline { 3 - 6 } & n=6 & 0 min & 30 min & 60 min & 120 min \\
\hline 1 & Normal & $91.42 \pm 0.92$ & $132.33 \pm 1.12$ & $117.29 \pm 1.11$ & $111.03 \pm 1.17$ \\
2 & Standard (Glibenclamide, $2.5 \mathrm{mg} / \mathrm{kg})$ & $94.01 \pm 0.73$ & $110.33 \pm 0.56^{*}$ & $83.09 \pm 0.97 *$ & $79.39 \pm 0.05^{*}$ \\
3 & Murrayanol $(50 \mathrm{mg} / \mathrm{kg})$ & $95.01 \pm 1.32$ & $123.33 \pm 1.48^{*}$ & $104.67 \pm 0.92^{*}$ & $92.01 \pm 0.37 *$ \\
4 & Murrayanol $(100 \mathrm{mg} / \mathrm{kg})$ & $103.09 \pm 1.67$ & $129.04 \pm 1.46$ & $108.31 \pm 1.87 *$ & $94.83 \pm 2.11 *$ \\
\hline
\end{tabular}

Normal Control- Vehicle $10 \mathrm{ml} / \mathrm{kg}$, Reading are values \pm S.E.M, $\mathrm{n}=$ Numbers of animals in each group, $* \mathrm{P}<0.05 \mathrm{v} / \mathrm{s}$ Normal control; One-way ANOVA followed by Dunnet $t$ test

FBS (Fasting Blood Glucose Level): Fasting blood sugar level was determined by using glucose oxidase peroxidase reactive strips.

TABLE 6: EFFECT OF MURRAYANOL ON FASTING BLOOD GLUCOSE LEVELS IN RATS

\begin{tabular}{|c|c|c|c|c|c|}
\hline \multirow[t]{2}{*}{ S. no. } & \multirow{2}{*}{$\begin{array}{c}\text { Treatment } \\
\mathbf{n}=6\end{array}$} & \multicolumn{4}{|c|}{ Fasting blood glucose level (mg / dl) } \\
\hline & & Day 0 & Day 5 & Day 10 & Day 15 \\
\hline 1 & Normal & $97.14 \pm 1.53 *$ & $94.17 \pm 1.25 *$ & $91.83 \pm 1.01 *$ & $88.67 \pm 1.15 *$ \\
\hline 2 & Diabetic control & $181.67 \pm 1.12$ & $189.11 \pm 0.88$ & $196.83 \pm 1.08$ & $199.18 \pm 1.31$ \\
\hline 3 & Standard (Glibenclamide, $2.5 \mathrm{mg} / \mathrm{kg}$ ) & $184.33 \pm 1.45$ & $127.55 \pm 0.76^{*}$ & $116.51 \pm 1.01 *$ & $107.67 \pm 1.14^{*}$ \\
\hline 4 & Murrayanol $(50 \mathrm{mg} / \mathrm{kg})$ & $180.11 \pm 1.83$ & $137.33 \pm 1.33$ & $125.83 \pm 1.34 *$ & $119.18 \pm 0.97 *$ \\
\hline 5 & Murrayanol (100 mg/kg) & $179.67 \pm 0.65$ & $135.65 \pm 1.50^{*}$ & $126.33 \pm 1.03 *$ & $116.52 \pm 1.08^{*}$ \\
\hline
\end{tabular}

Values expressed as mean \pm S. E. M.; $\mathrm{n}=$ no. of animals in each group. $* \mathrm{p}<0.05$ significant $v s$. diabetic control. One-way ANOVA followed by Dunnet t-test

\section{Effect of Murrayanol on Serum Lipid Profile:}

TABLE 7: EFFECT OF MURRAYANOL ON SERUM LIPID PROFILE IN RATS

\begin{tabular}{ccccccc}
\hline S. no. & Treatment $\mathbf{n = 6}$ & TG & TC & HDL & LDL & VLDL \\
\hline 1 & Normal & $88.86 \pm 1.04^{*}$ & $55.52 \pm 0.94^{*}$ & $23.88 \pm 0.73$ & $13.45 \pm 0.87^{*}$ & $18.72 \pm 0.20$ \\
2 & Diabetic control & $136.52 \pm 1.54$ & $96.56 \pm 1.03$ & $15.55 \pm 0.83$ & $53.73 \pm 0.41$ & $27.29 \pm 0.33$ \\
3 & Standard & $101.56 \pm 1.07^{*}$ & $57.21 \pm 1.08^{*}$ & $19.20 \pm 0.52$ & $17.35 \pm 0.44^{*}$ & $20.85 \pm 0.21$ \\
& (Glibenclamide, $2.5 \mathrm{mg} / \mathrm{kg})$ & & & & & \\
4 & Murrayanol $(50 \mathrm{mg} / \mathrm{kg})$ & $115.87 \pm 1.14^{*}$ & $75.27 \pm 1.20^{*}$ & $14.26 \pm 0.39$ & $37.84 \pm 0.86^{*}$ & $23.17 \pm 0.23$ \\
5 & Murrayanol $(100 \mathrm{mg} / \mathrm{kg})$ & $107.06 \pm 1.04^{*}$ & $65.19 \pm 1.24^{*}$ & $18.59 \pm 0.38$ & $25.23 \pm 1.40^{*}$ & $21.37 \pm 0.30$ \\
\hline
\end{tabular}

Values expressed as mean \pm S. E. M.; $n=$ no. of animals in each group. * $\mathrm{p}<0.05$ significant Vs diabetic control. One-way ANOVA followed by Dunnet t-test

Preparation of Particulate System: particles formed. The optimized formula used for Microparticles were optimized on the basis of $\%$ further work. The solvent evaporation method has entrapment, drug content, stirring time and no. of been used in which Glyceryl monostearate was 
dissolved in acetone and ethanol $(1: 1 \mathrm{v} / \mathrm{v})$ in a water bath at $60{ }^{\circ} \mathrm{C}$ and this was added to aqueous phase (distilled water) under mechanical agitation for $45 \mathrm{~min}$. This was subjected to centrifugation at
$4000 \mathrm{rpm}$ for $10 \mathrm{~min}$. Resuspended in water which results in formation of solid particles. Finally the microparticles were collected by filtration and are washed with demineralized water.

TABLE 8: OPTIMIZATION OF DRUG: POLYMER RATIO

\begin{tabular}{ccccc}
\hline $\begin{array}{c}\text { Formulation } \\
\text { code }\end{array}$ & $\begin{array}{c}\text { Ratio } \\
\text { (Murrayanol: Polymer) }\end{array}$ & $\begin{array}{c}\text { Average size } \\
(\boldsymbol{\mu m})\end{array}$ & $\begin{array}{c}\text { No. of particles per } \\
\mathbf{m m}^{\mathbf{3}} \times \mathbf{1 0 0 0}\end{array}$ & \% Entrapment \\
\hline MPL-1 & $9: 1$ & $2.23 \pm 0.35$ & $27 \pm 2.5$ & $64.4 \pm 1.2$ \\
MPL-2 & $8: 2$ & $2.34 \pm 0.54$ & $28 \pm 2.2$ & $68.8 \pm 0.98$ \\
MPL-3 & $7: 3$ & $2.69 \pm 0.57$ & $36 \pm 1.9$ & $70.5 \pm 1.10$ \\
MPL-4 & $6: 4$ & $2.75 \pm 0.15$ & $28 \pm 1.6$ & $65.4 \pm 1.43$ \\
MPL-5 & $5: 5$ & $2.77 \pm 0.24$ & $23 \pm 1.5$ & $64.8 \pm 0.85$ \\
\hline
\end{tabular}

*Data are shown as mean \pm SD $(n=3)$

\section{Characterization of Microparticles:}

Particle Size and Shape: Microparticles were visualized under Philips Morgani 268 Transmission Electron Microscope. A drop in the different formulations was placed on different carbon-coated copper grids to leave a thin film on the grids. Then, the film was negatively stained with $1 \%$ phosphotungstic acid (PTA) by placing a drop of the staining solution on to the film and the excess of the solution was drained off with a filter paper. The grid was allowed to dry thoroughly and formulations were viewed under a transmission electron microscope and photographs were taken at suitable magnification Fig. 4.

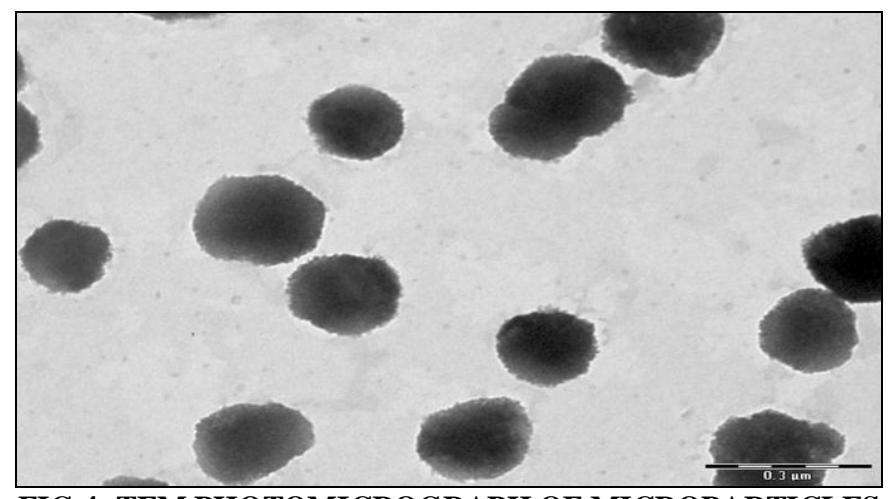

FIG 4: TEM PHOTOMICROGRAPH OF MICROPARTICLES

Particle Size and Distribution: The size and size distribution of particles was determined using a laser diffraction particle size analyzer (Cilas, 1064 L, France). The particulate suspension was dispersed in distilled water and then it was put into the sample chamber of particle size analyzer and measurement of particle size was carried out in Table 8.

Entrapment Efficiency: 1 g sephadex G-75 was allowed to swell in $10 \mathrm{ml}$ of $0.9 \% \mathrm{NaCl}$ solution in distilled water in a glass screw-capped bottle for 5 $\mathrm{h}$ at room temperature. The hydrated gel was filled to the top in the barrel of $1 \mathrm{ml}$ disposable syringe plugged with the Whatman filter pad. The barrel was then placed in the centrifuge tubes. The tubes were centrifuged at $2000 \mathrm{rpm}$ for $3 \mathrm{~min}$ to remove the excess saline solution. Eluted saline was removed from the centrifuge tubes and exactly 0.2 $\mathrm{ml}$ of suspension (undiluted) was applied dropwise on the top of the gel bed in the center. Columns were again centrifuged at $2000 \mathrm{rpm}$ for $3 \mathrm{~min}$ to expel and remove void volume containing microparticles into the centrifuge tubes. Elute was removed and $0.25 \mathrm{ml}$ saline was applied to each column and centrifuged as previously. The amount of drug entrapped in the particles was then determined by disrupting the particles followed by filtration and subsequent determination of the drug content using spectrophotometric method Table 8.

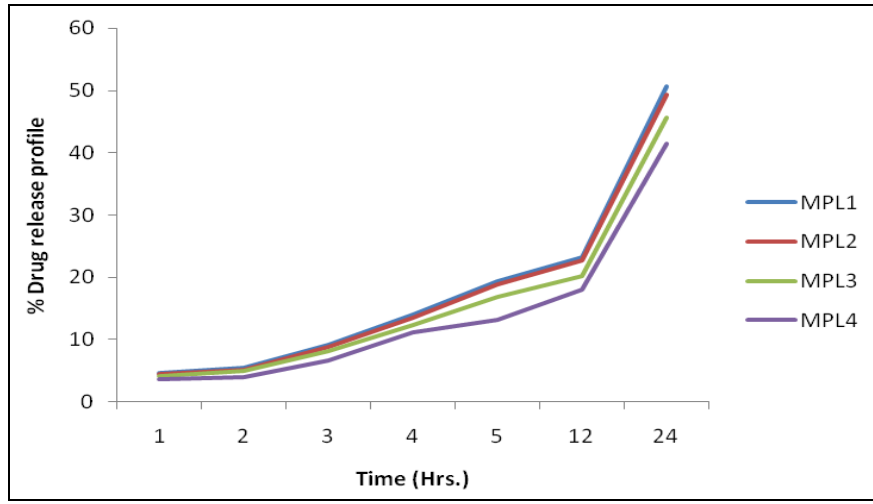

FIG. 5: IN-VITRO DRUG RELEASE PROFILE

In-vitro Drug Release: $1 \mathrm{ml}$ of pure suspension was placed in a dialysis tube, which in turn was placed in a beaker containing $20 \mathrm{ml}$ of PBS (7.4 $\mathrm{pH})$. The solution containing the dialysis tube was stirred on a magnetic stirrer while keeping the temperature constant at $37 \pm 1{ }^{\circ} \mathrm{C}$ throughout the study. Samples were withdrawn at different time 
intervals with subsequent analysis for drug-using Shimadzu $1601 \mathrm{UV}$ spectrophotometer at $210 \mathrm{~nm}$.

RESULTS AND DISCUSSION: Isolated Murrayanol shows an effective decrease in blood glucose level as compared to the standard glibenclamide drug which is tested by animal studies. The drug release pattern also altered with the microparticles prepared by the solvent evaporation method shows improved drug release profile. In-vitro drug release studies show that drug release controlled over a prolonged period of time i.e. after 24 h. $45.7 \%$ drug was released, this will also decrease the dosing frequency of active constituent.

CONCLUSION: After the development of polymeric microparticles containing murrayanol shows effective management of diabetes in animals and release also modified because of carrier system which results in zero-order drug delivery in the body. We used drugs of herbal origin which is again a benefit to get rid of the continuous use of synthetic drugs daily, which ultimately gives side effects on the body.

ACKNOWLEDGEMENT: I would like to thank my supervisor and faculties for their support and motivation. I also thankful to S. K. Traders for chemicals and Holkar Science College, Indore for the identification of plants.
CONFLICTS OF INTEREST: The authors declare that there is no conflict of interest.

\section{REFERENCES:}

1. Waghmare AN, Tembhurne SV and Sakarkar DM: Phytochemical analysis and in-vitro antioxidant properties of M. koenigii (L.). American Journal of Phytomedicine and Clinical Therapeutics 2015; 3 (5): 403-16.

2. Igara CE, Omoboyowa DA, Ahuchaogu AA, Orji NU and Nduknve MK: Phytochemical and nutritional profile of Murraya koenigii (L.) leaf. Journal of Pharmacognosy and Phytochemistry 2016; 5(5): 07-09.

3. Nishan M and Subramanian P: Murraya koenigii (curry leaves)- A review on its potential. International Journal of Pharmaceutical Technology and Research 2016; 7(4): 56672.

4. Taylor RN, Links MR, Taylor J and Kruger MC: Sorghum condensed tannins encapsulated in kafirin microparticles as a nutraceutical for inhibiton of amylases during digestion to attenuate hyperglycaemia. Journal of Functional Foods 2015; 12: 55-63.

5. Nagendra R, Charan CS, Joshi $\mathrm{KH}$ and Jayanthi C: Preparation and evaluation of microparticles containing oxybutynin chloride for controlled release. Asian J Biomed Pharm Sci 2015; 5(41): 15-17.

6. Parikh R and Dalwadi S: Preparation and characterization of controlled release poly-E-caprolactone microparticles of isoniazid for drug delivery through pulmonary route. Powder Technology 2014; 264: 158-65.

7. Jain M, Gilhotra R, Singh RP and Mittal J: Curry leaf (Murraya koenigii): a spice with medicinal property. MOJ Biol Med 2017; 2(3): 236-56.

8. Goyal AK, Garg T, Bhandari $S$ and Rath G: Nanostructures for drug delivery, Elsevier 2017; 685-87.

9. Kavitha M: Antibacterial and antioxidant activity of leaf organic extracts of local cultivars of Murraya koenigii from TN. Biotechnological Communication 2017; 10(2): 359-64.

\section{How to cite this article:}

Salvi N and Choudhary GP: Development and characterization of polymeric microparticles containing Murraya koenigii leaves extract for management of diabetes mellitus. Int J Pharm Sci \& Res 2020; 11(2): 774-79. doi: 10.13040/IJPSR.0975-8232.11(2).774-79.

All @ 2013 are reserved by the International Journal of Pharmaceutical Sciences and Research. This Journal licensed under a Creative Commons Attribution-NonCommercial-ShareAlike 3.0 Unported License.

This article can be downloaded to Android OS based mobile. Scan QR Code using Code/Bar Scanner from your mobile. (Scanners are available on Google Playstore) 